\title{
6. The political cartoonist and the editor
}

\section{ABSTRACT}

New Zealand Herald cartoonist Malcolm Evans was dismissed from the paper after he refused to follow his editor's instruction to cease cartooning on the Israeli-Palestinian conflict. Members of the Jewish community were upset by a number of his cartoons, drawn during the first half of 2003 . Evans is not alone among cartoonists to attract the anger of Jewish community lobbies and the hesitation of their editors when presenting cartoons dealing with the activities of the Israeli government. Cartoonists Tony Auth (Philadelphia Inquirer) and Michael Leunig (The Age) have also presented controversial cartoon commenting on the Israeli Government and, with Evans, defend their work on the grounds that while cartoons may offend an audience the content is not necessarily wrong. Cartoonists fiercely defend their licence to mock politicians, governments and states. This article examines this defence and the space within which cartoonists examine political subjects. We analyse the parameters within which mass circulation newspaper editors operate, principally in the Australian context. We defend a wide licence for cartoonists and argue that this licence represents an important measure of free speech in an era when the threat of terrorism looms large on national political agendas.

\section{HAYDON MANNING and ROBERT PHIDDIAN \\ Flinders University}

\section{What do cartoons do?}

$\mathrm{P}$ OLITICAL CARTOONS serve various functions in the forum of pub lic opinion, and it is as easy to exaggerate their importance as their insignificance. They can aim for anything from light relief to prophetic clarification of a major public issue; they are read by hundreds of thousands of people who are sufficiently engaged in politics to scan the opinion pages 
of newspapers one day. These pages are superseded by other cartoons and issues the next day. What may make one reader roar with the laughter of sympathetic recognition, may merely bemuse another. Cartoons are a hit and miss affair. They share this inconsistency of cause and effect with the two genres of communication they belong to: media commentary and political satire. Cartoons are liminal things, poised somewhere between being 'the most influential thing in the paper' and 'just a joke', and this gives them a special licence for provocative statement (Seymoure-Ure, 1997; Press, 1981 and Gombrich, 1978).

They exploit their licence in a range of ways that can, for the purpose of analysing their role as political commentary, be placed on a spectrum that ranges from 'not serious at all' at one end to 'very serious indeed' at the other. Practising cartoonists tend to recognise a broad division of territory in their work between satire (where the cartoon seeks to make a significant point through humour or even attack) and gags (where the joke is there to entertain readers). Few claim to be devoted merely to one sort of cartoon or the other, and all worry about the sort of balance they strike. Too much satire, especially if it is too consistent in the opinions it sponsors, and you run the risk of losing all but the converted from your audience; too many gags and you are a mere entertainer, wasting your opportunity to do some good in public life. Another thing that haunts cartoonists is the fear that their work evaporates without having any real effects. It is true that very few politicians have resigned, apologised, or changed policy as a result of a particularly bruising cartoon; indeed, politicians often request the original cartoons that caricature them and their policies. Still, no form of commentary has much success in transforming public opinion, and cartoonists need to recognise (as they routinely do) that they are part of the public debate - as Bill Leak, cartoonist with the Australian points out.

I work for a newspaper where I whittle and grind away in the interesting position of being part of the political process but very much on the periphery of it. Nevertheless, from the periphery I'm able to throw in little incendiary bombs, stir things up every now and then and, on a good day, kick the bastards really hard. It's a deeply satisfying way to make a living (Interviewed, 1 May 2004).

There is plentiful evidence that they can get under the skin of even the most 
hardened politicians. Examples came from David Low's loathing of Billy Hughes and Adolph Hitler to Bill Leak's dislike of John Howard

So, while cartoonists sometimes despair of their lack of influence and others fear that they have too much influence (Hogan, 2001), it may be useful to pause and summarise the sorts of influence cartoons can have. We have done this more systematically elsewhere but would point out here that cartoons are a part of opinion-formation in liberal democracies that enjoy (and in our opinion, should enjoy) a special licence to make exaggerated and comic criticisms of public figures and policies (Manning \& Phiddian, 2004). Cartoonists are employed by newspapers principally to entertain readers and to provoke thought; often they are the part of the paper least disciplined by an adherence to any editorial line. Consequently, cartoons comment from a generalist perspective and, when they work well, they may simplify complex issues to a single frame (eg see below Spooner's 'Globalisation' and Petty's comment on patriotism). This can lead to over-simplification and occasionally sponsor public cynicism, but the risk of this is often worth it for the shafts of lateral intelligence.

Because the opinion pages of newspapers are read by a self-selecting minority of the voting public - people with at least an active spectator's interest in politics - cartoons do not have a direct effect on public opinion. Below we critique Michael Hogan's argument that political cartoons promote a disturbing cynicism toward leaders, parties and parliaments. Voters disengaged from the game of politics do not read them and those engaged enough to read newspapers tend to have elaborated political opinions from which they are not easily detached. However, within this substantial and influential minority of people where most policy debate occurs cartoonists play a significant range of roles. They can speak up for the ordinary, bewildered citizen, as is the case with Kudelka's 1998 election campaign cartoon or for a persecuted minority, as with Nicholson's comment on white prejudice toward Aborigines (see overleaf).

They can fix the images of public figures in our heads through caricature: Bill Leak's caricature of Howard (see overleaf) is arguably the most memorable among the current crop of Howard caricatures.

They can suggest alternatives to the received wisdom and sound the alarm when more disciplined thought patterns are lulled into a false sense of normalcy. John Spooner's reflection on globalisation is almost unforgettable in 

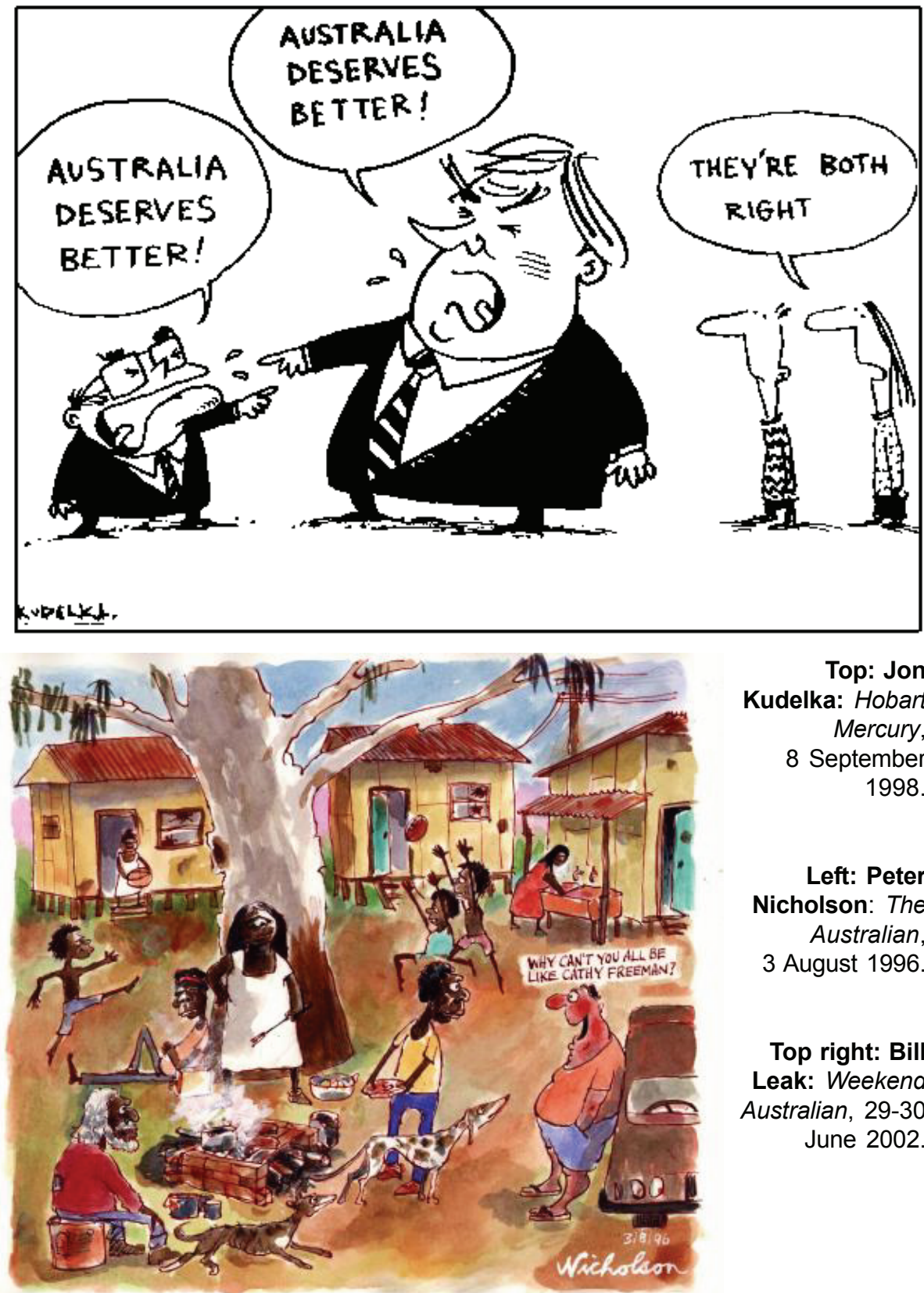

Top: Jon

Kudelka: Hobart Mercury, 8 September 1998.

Left: Peter Nicholson: The Australian, 3 August 1996.

Top right: Bill Leak: Weekend Australian, 29-30 June 2002. 


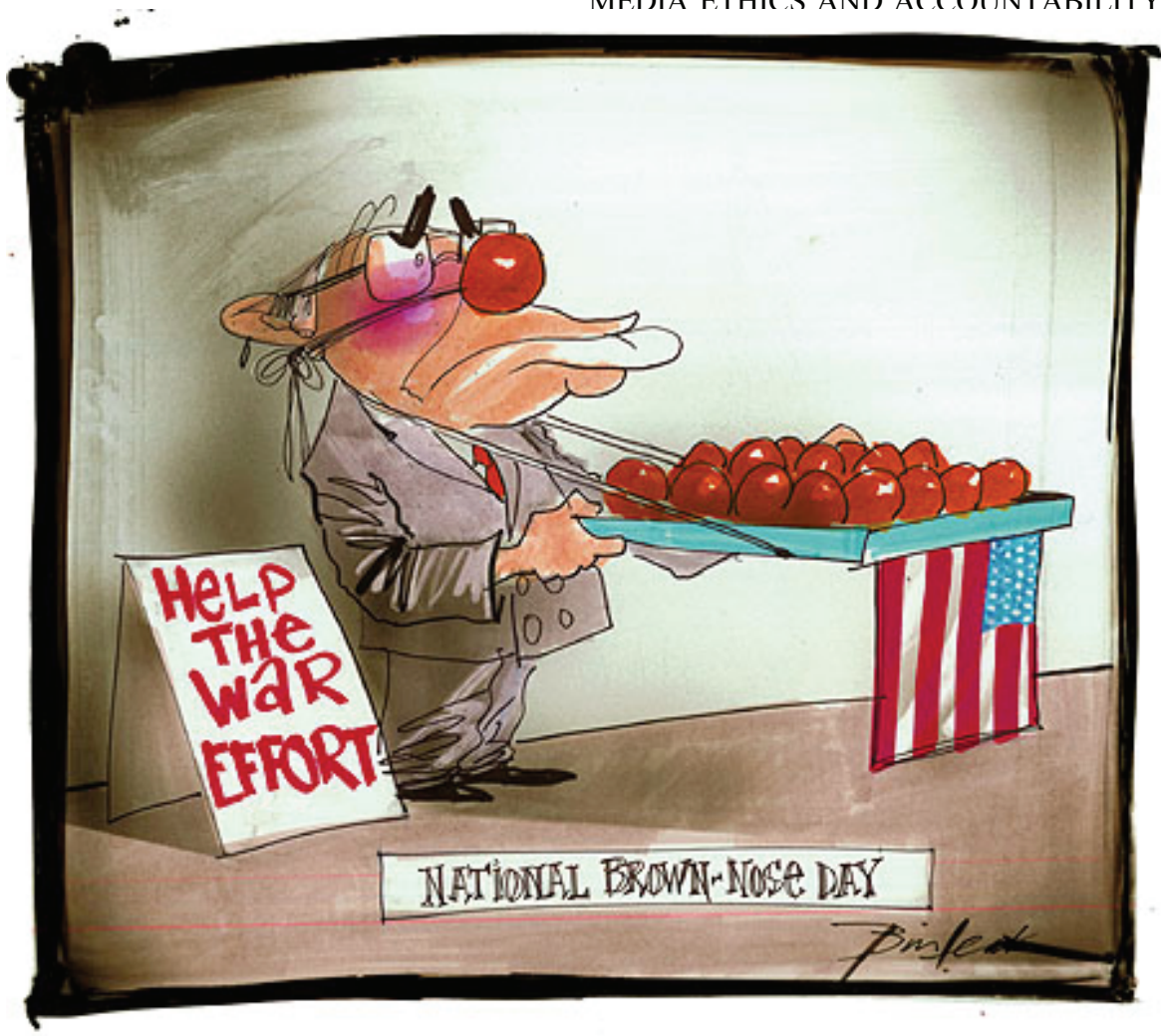

its powerful use of metaphor where the mother may be seen as our government and the child the creature of neo-liberalism - much loved yet foreboding. They can question waves of hysteria. They can force dishonest political (or corporate, or whatever) conduct to shame in our increasingly shameless society. In other words, they are a part of the media with special characteristics and potential, and that exposes them to a range of formal and informal pressures.

It is the purpose of this article to outline these pressures as they apply to the work of political cartoonists, and to discuss the case of Malcolm Evans' sacking from The New Zealand Herald. Some of these pressures involve defamation law and can be described as censorship, while others make more amorphous influences on what cartoonists choose to discuss in their work, and how they choose to discuss it. Basic to any satirical work is that it should question received opinions and affront decorum, but this does not occur in a 

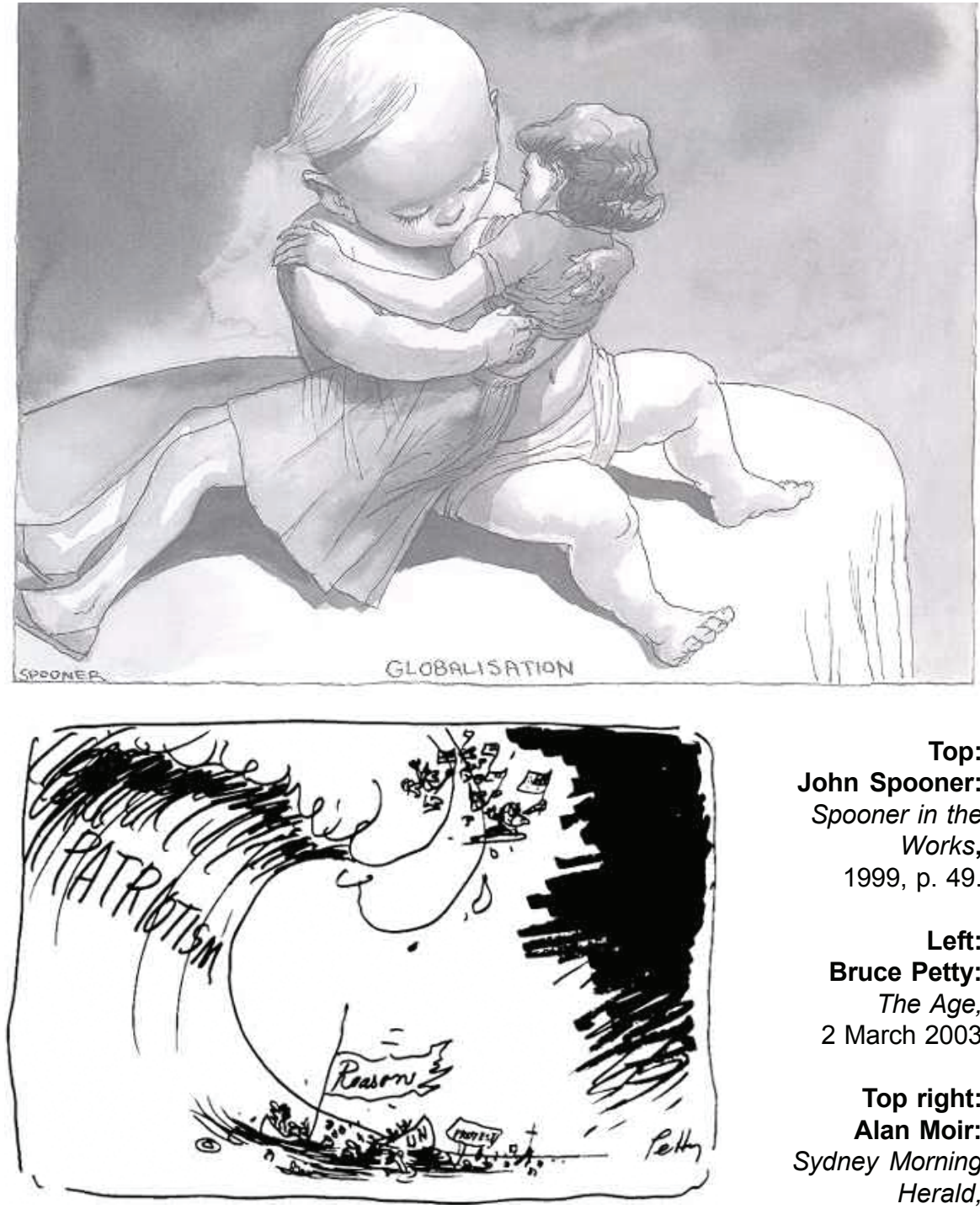

Top: John Spooner: Spooner in the Works, 1999, p. 49.

Left: Bruce Petty: The Age, 2 March 2003

Top right: Alan Moir: Sydney Morning Herald, 28 August 2002. 


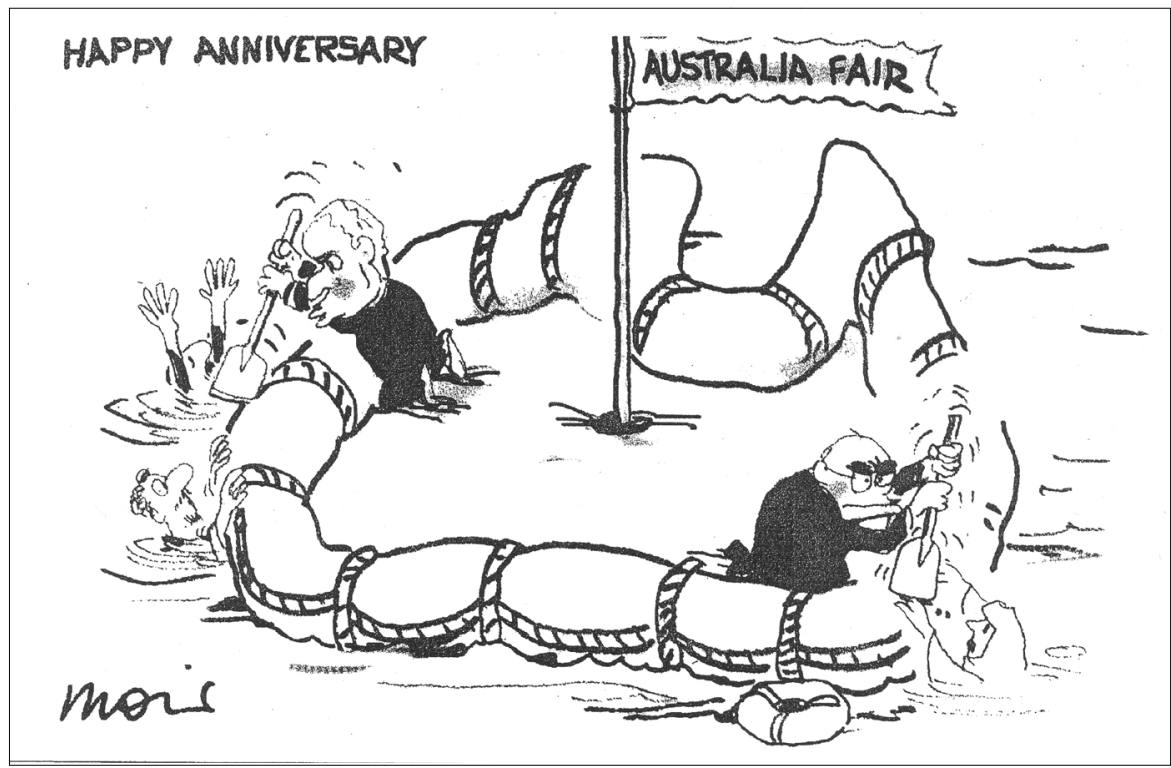

vacuum of pure satirical aggression. Cartoonists act in corporately-owned newspapers - some of the most conservative organs of opinion formation within patterns of decorum (see below) that have built over more than a century of editorial and political cartooning beginning with magazines such as The Bulletin and spreading through British, US, and Australasian newspapers. That they so often test those limits is one of the many things that make them so interesting. In this time of increasingly coercive war against the amorphous concept of terror, attention to the function of cartoons in the ecology of political debate may shed some light on the nature of free speech. We are treating cartoonists as interesting in themselves, and as canaries sent down the mine shaft of public debate to discover how fresh the air is there, how safe it is for freedom of speech.

\section{The Malcolm Evans affair}

Malcolm Evans worked as editorial cartoonist with The New Zealand Herald for seven years before he was dismissed for refusing to cease presenting to his editor, Gavin Ellis, cartoons concerning the Israeli-Palestinian conflict. Demonstrations outside the paper's office ensured that and the case was reported widely. President of the Cartoonists and Illustrators Association of 
New Zealand and an award-winning cartoonist, Evans says he always respected the editor's right to reject his cartoons but objected to being dictated to regarding their content. He argued in a television interview that 'the cartoonist's art is viewed by the reader every day as part of a greater whole. For any portion of that to be genetically engineered out is, in my view, a fraud on the reader' (Mediawatch, 2003). A number of Evans' cartoons published during the first half of 2003 upset the NZ Jewish community and, it appears, under pressure the newspaper decided to silence the critics by directing that Evans no longer comment on the conflict. Two cartoons on the opposite page are among the strongest for their condemnation of Israeli state policy.

The cartoon depicting the Star of David caused such controversy that Ellis published an apology. Having initially rejected the cartoon for publication, Ellis regretted that the paper's 'production processes' failed and it 'found its way into the newspaper'. He stressed that the paper's policy aims 'to separate the policies and actions of an elected government from one of the world's great religions' (Harvey, 2003). For Evans, this seriously misses the point:

\footnotetext{
The cartoonist's art is all about trying as best he might to suggest a viewpoint that might strike a chord. It's not that one sets out to be controversial, it's simply to say- hey what about? What do you think of this? Is this reasonable? And in my view I felt that if we could look at say what was happening in Zimbabwe and what Mr. Mugabe is doing, it's fair and reasonable that we should similarly be able to look at the situation in Palestine...(Mediawatch, 2003).
}

Evans recognised that his cartoons and particularly his 'Ap*rtheid' cartoon was likely to cause 'quite a stir' but he underestimated his editor's capacity to misconstrue the cartoon as a comment on Judaism that could be viewed as anti-Semitic, rather than a comment on Zionist politics. Upset by the accusation of anti-Semitism, Evans stated publicly his admiration for the contribution of Jewish culture to Western society but reserved the right to be critical of Zionism - 'I'd personally like to put on record that I think that our society, our culture owes so much to the Jewish culture. To Jewish artists, historians, in almost every respect from the Old Testament right through to the present day, but in my view Zionism is something else' (Mediawatch, 2003).

Striking a chord, but which chord, is the issue at stake in many debates 
MEDIA ETHICS AND ACCOUNTABILITY

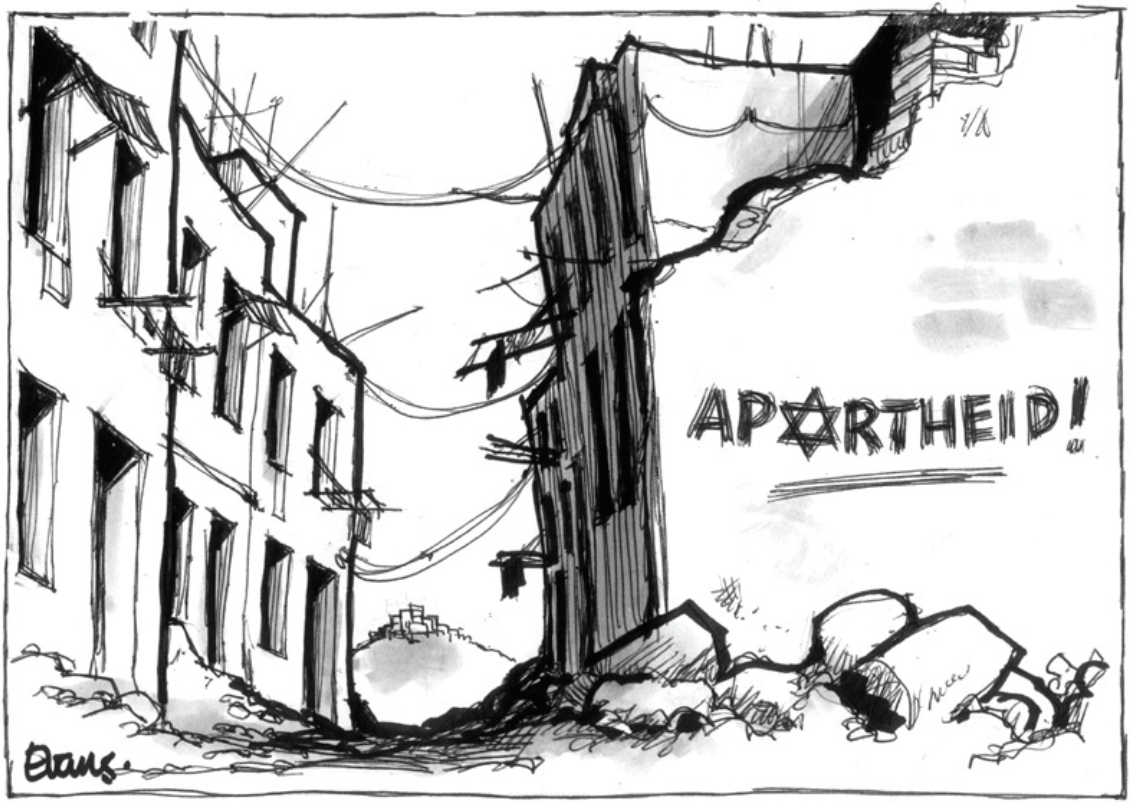

Malcom Evans: New Zealand Herald, 13 June 2003 (top) and New Zealand Herald, July 2003.

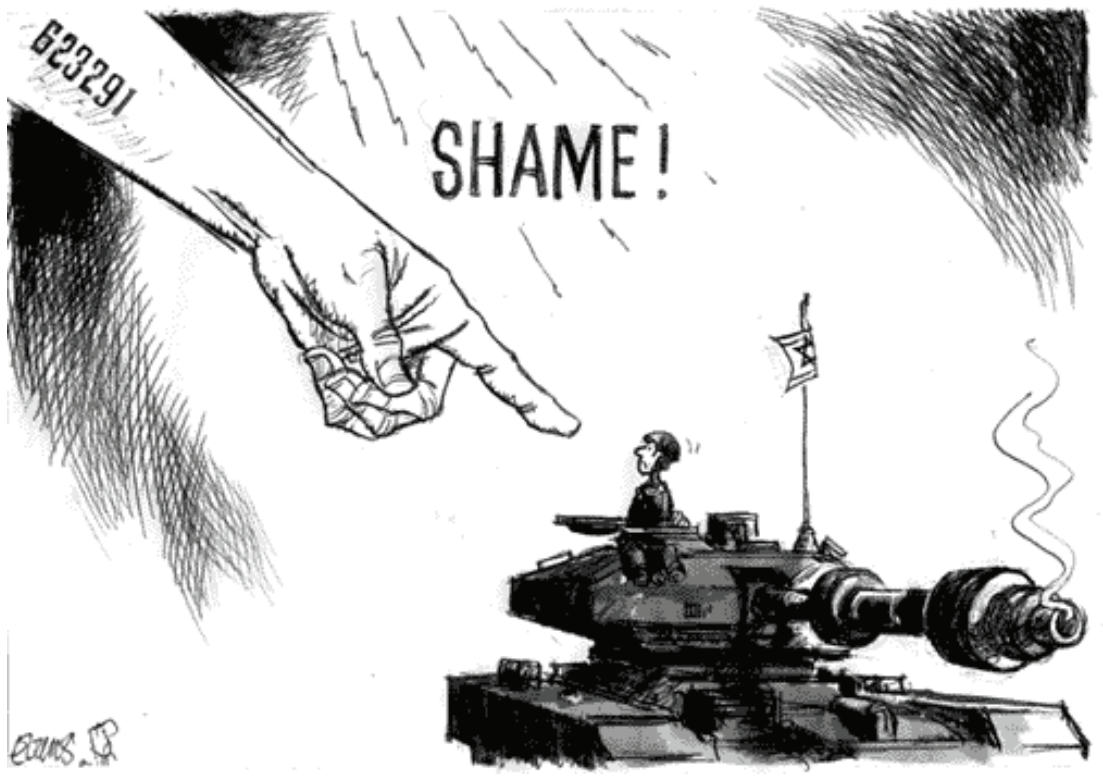

PACIFIC JOURNALISM REVIEW 11 (2) 2005135 
over what is admissible or otherwise in the mainstream mass media. Obviously, for many Jews, use of symbols such as the Star of David and criticism of the Israeli Government implies an anti-Semitic viewpoint. Laura Kam Issachoroff, speaking on behalf of the Anti-Defamation League, observed that 'There's definitely a line between political discourse that's appropriate and anti-Semitism... [and] We understand that cartoons by their very nature go very close to that line to make a graphic point'(Keyer, 2003). Cross cultural sensitivities are a condundrum for editors and cartoonists alike and, broadly speaking, what one national group find funny others do not. Showing cartoons - as we have found - depicting national leaders being lampooned may solicit vastly different responses from Western audiences compared with an Asian audience where greater reverence for 'the leader' is generally part of political and social mores. Thus, what is funny varies greatly across cultures and this point is alluded to in an interview with Evans published in the Jewish newspaper, Haaretz. Interestingly the paper quotes two Jewish cartoonists' view that 'Jews simply don't understand the language and the humour of cartoons... [seeing] every attack on Israel as a direct attack on Judaism'(Cohen and Ahronoth cited in, Sara Leibovich-Dar 2003). Whether or not this is a fair observation is not for us to adjudicate but it does raise a perennial problem for cartoonists, namely, that their craft involves, 'laughing with knives' and this inevitably causes pain and, sometimes, anger. The point we make is that within the context of the liberal-democratic polity the 'court jesters' should not be censored so as to protect such cultural sensitivities where it can be shown that their cartoons are unequivocally open to interpretation. If a cartoon is open to only one interpretation and this involves racist comment, crude bad taste or high likelihood of libel (more on these matters below) then an editor is well within his or her bounds to refuse publication.

In part the problem for Evans lies with his use of the Star of David, a national symbol of Israel and of Jewish people worldwide, which is also readily associated with Zionism. In directing Evans to no longer comment on a particular issue Ellis has bowed to Jewish sensitivity and fundamentally missed the point. Evans' satire is directed at a government which, while varying over time with respect to its intent and degree of commitment may, nevertheless, be viewed as following Zionist predilections. Evans was not alone in facing censorship on matters concerning the Israeli government as the same dilemma confronted one of Australia's best known and admired cartoonists, Michael 
Leunig. One of his cartoons (below) makes ostensibly the same point as Evans, namely that Israeli government actions are questionable. In Leunig's case his editor, Michael Gawenda, managed to ensure the cartoon was not published saying it was simply 'inappropriate' (ABC television, 2002). The cartoon depicts a Jew approaching a concentration camp at two different points in history; it surfaced subsequently on the ABC television's Media Watch program and, thereby, entered the public arena. Without the Star of David the figure approaching the concentration camp gates is less identifiable as a Jew, especially for a younger audience. The point at issue for cartoonists is the need to quickly identify their subject's location and often that entails the use of symbols, exaggerated characteristics or a name tag. But, as can be seen in these instances, the use of religious symbols may be used as an excuse for censoring the message.

Leunig believes that his cartoon is 'sympathetic to all Jews who ever suffered' but stresses that 'sympathy is not always expressed with sugar' and

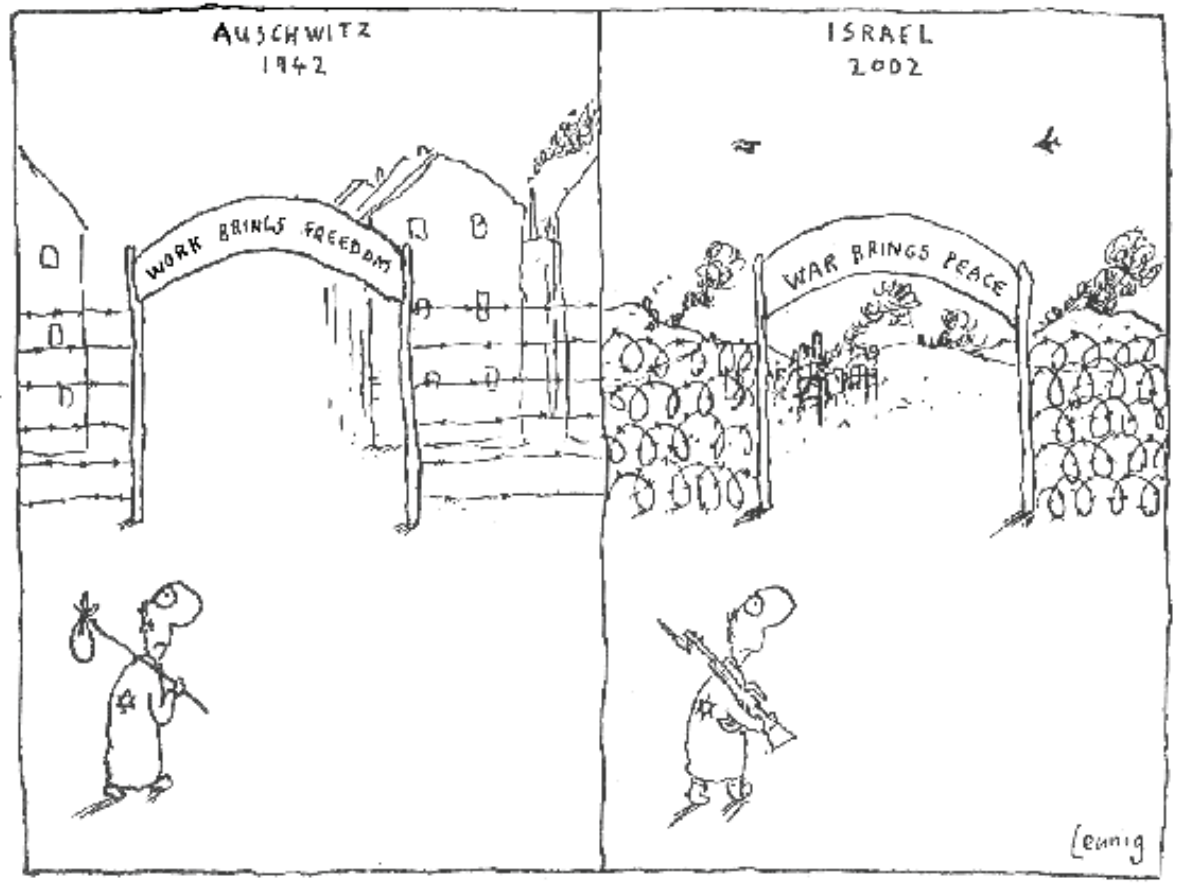

Michael Leunig: ABC Media Watch, 6 May 2002. 
that it was his editor's religion that explains the censorship (ABC Televison, 2002).

At about the same time as the Evans' resignation the Philadelphia Inquirer's editor, Amanda Bennett, defended her decision to publish Pulitzer Prize winning editorial cartoonist, Tony Auth's, provocative use of the Star of David to symbolise the imprisonment of the Palestinians.

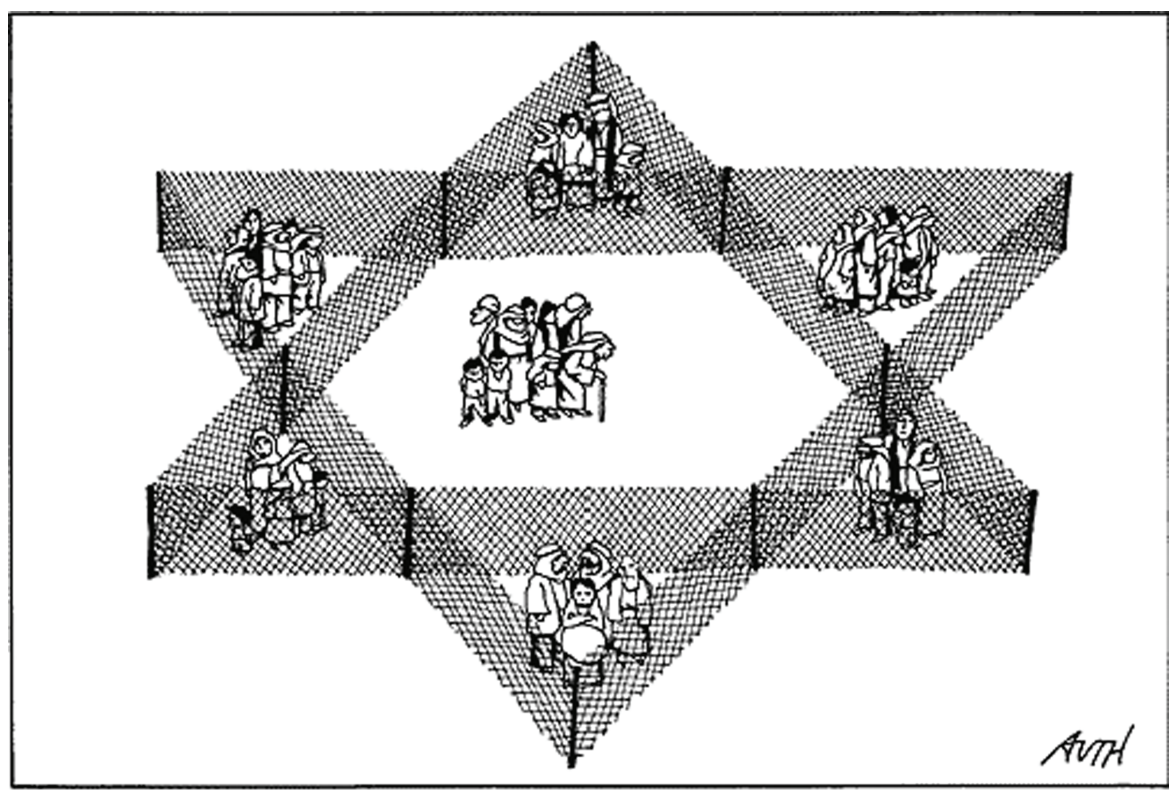

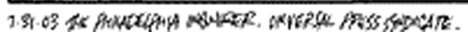

Tony Auth: Philadelphia Inquirer: 31 July 2003.

The cartoon plays upon a literal interpretation of the Israeli Government's effort to segregate Jews and Palestinians by building a huge concrete wall. Amid considerable controversy - which quickly became international with the cartoon's widespread publication on the internet-Bennett defended her decision:

I believe that it's possible, particularly for a cartoonist, to take a critical position on a matter involving Israel without being labeled as anti-Semitic' (Schleider, 2003). Writing with a colleague in the Philadelphia Inquirer a balanced account of the controversy she noted that for some 
people the cartoon implied the misuse of a sacred symbol and 'had the effect of criticising the Jewish faith and people as a whole, not just the government' (Bennett \& Satullo, 2003). For his part, Auth stressed that he'd been critical of both Israel and the Palestinians; 'It was never my intention to impugn the Jewish faith or make some sort of allusion to the Holocaust. It is unfortunate that anyone interpreted the cartoon in those ways'(quoted in Bennett \& Satullo, 2003). Having published many cartoons critical of Palestinian suicide bombers he appealed to the intelligence of his readership to understand that his message was not racist, 'It's only possible to regard me and my work as anti-Semitic by selectively looking at certain cartoons'. (Auth quoted in Levy \& Perloe, 2003)

\section{A brief history of cartoonists' independence}

As cartoons have to be funny, they are naturally harder than news reporting or opinion writing to hold to an editorial line. Market forces actually militate in favour of maximum freedom for cartoonists, because editors or proprietors inclined to choose a cartoon that says what they want it to say over a stronger or funnier alternative are imperilling the future success of their paper. Moreover, cartoons have the court jester's licence to broach unorthodox perspectives because they are not 'serious' and can slip more easily under the guard of doctrinal policing than 'straight' reporting or comment. Still, cartoonists' freedom is only relative, and only relatively recently won. Later in this section we will survey the formal and informal constraints on cartoonists in Australian mass-market newspapers (the rules are quite different for specialist journals where, generally speaking, a much stricter requirement to toe a party line is evident), but let us first scan a little history about how we got to this point.

In the second half of the nineteenth century, when cartooning in periodicals like the London and Melbourne Punches and the Sydney Bulletin began, it was unusual for cartoonists to originate their own ideas. They were conceived of as comic illustrators who were fed ideas by the editorial meeting. Often, indeed, they did not even get to write their own captions. Some like Livingston Hopkins ('Hop') at the Bulletin fancied themselves as commentators who originated and completed their own jokes, but others like Phil May 'had to have the whole scene and idea laid out for him' (Lindesay, 1970, p. 10; see also Geipel 1972). The career of David Low in New Zealand, Australia, and England did much to establish the cartoonist as 
an independent political commentator on the editorial page of newspapers, but not every antipodean paper had an editorial cartoonist (e.g. the Melbourne Age before the advent of Les Tanner in the 1960s) or treated those they had with the sort of respect that Low could command.

In 1945, Frank Packer wanted the Daily Telegraph in Sydney to take a more explicitly conservative line, and expected his cartoonists to obey orders:

In November Will Mahoney refused to sign cartoons attacking unions, telling Penton [the editor] that the Telegraph should take responsibility for them. After the former Labor Daily cartoonist [ie Mahoney] was sacked his replacement, George Finey, resigned over the same issue. The AJA [Australian Journalists' Association] unhappily concluded that they had no redress under the current award (Griffen-Foley, 1999).

This moment of brute proprietorial power is interesting, because it shows an expectation from consecutive cartoonists of a left-wing bent. They should be free at least to withdraw their imprimatur from commentary they disagreed with. That Packer did not agree with them shows what was then becoming an old-fashioned belief that cartoons should be subordinate to the paper's editorial line. Maybe it was just a genetic predisposition to get his own way. So far as we know, this is the last occasion in Australian media history when cartoonists were directed on pain of sacking to treat a particular topic in a particular way. Cartoons have been refused from time to time, and many a more or less helpful 'suggestion' of topic matter or slant has been made, but cartoonists in the post-war period have managed to exercise a freedom to choose and refuse their own topics. That Malcolm Evans felt it an intolerable constraint on his rights to be banned from cartooning on one topic area shows how far things have traveled in the Australasian context.

Consequently, in recent decades, the pressures on cartoonists have been less explicit than editorial direction, but real enough nonetheless. The precise status of cartoons under the laws of defamation is unclear, and worthy of detailed analysis in another place. In what remains of this paper, however, we will focus on the less formal pressures, on and within, newspapers that are deployed to restrain the exercise of satirical licence. 


\section{Internal editorial and corporate pressures}

Australian cartoonists do tend to have a fairly free hand. We know of no recent occasion where an editor or proprietor of a major daily has been known to direct a cartoonist to a particular topic, and only the Evans case where an entire topic area has been banned. Most cartoonists accept the right of editors not to run individual cartoons because they find them offensive, pointless, or inaccurate; editors are paid to edit, after all. But cartoonists expect and largely receive the right to cartoon against their newspaper's general editorial line where they see fit. A current illustration might be called the case of Peter Nicholson versus Rupert Murdoch. The Murdoch media around the world (from Foxtel to the Adelaide Advertiser) have been proverbially enthusiastic about the US invasion of Iraq, and the editorial position of The Australian has not been ambiguous. And yet, a Peter Nicholson's front page pocket cartoon appears in The Australian alongside the banner headline, 'We'll fight without the UN: Howard'. The cartoon mocks Prime Minister Howard at a time when he is trying to justify committing Australian troops to the war against Saddam Hussein's regime. He suggests that the self-proclaimed war leader is a hypocrite by reminding readers of his cynical use of asylum seekers during 2001 election campaign.

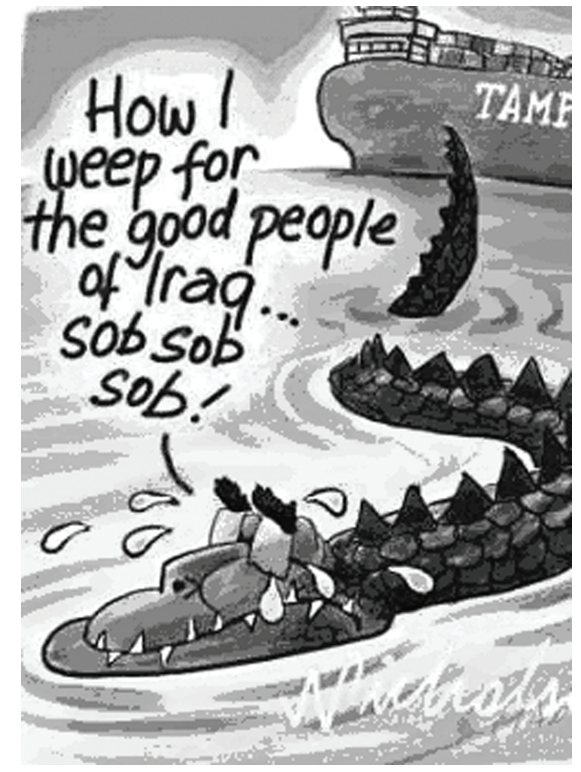

Peter Nicholson:

The Australian, 14

March 2003. 
Commitment of the nation's armed forces to war rates among the gravest of policy matters before government. Therefore, to find the Prime Minister portrayed as a hypocrite and on the front page of one of the country's leading broadsheets underlines the freedom cartoonists currently enjoy. Many other examples of cartoonists' vehement opposition to the commitment of Australian troops can be found during early 2003. Subsequently their general tenor is to contradict quite starkly the editorial and views expressed on the op-ed pages.

Some qualifications should be noted to this rosy picture of independence. How long a cartoonist can remain opposed to the editorial line of a paper before something gives way is an interesting question that would require detailed historical research to establish. It is also arguable that a paper might retain a dissenting cartoonist (or columnist) as a badge of pluralism that the rest of the paper belies. Finally, newspapers can, over time employ cartoonists whose values suit an editorial approach. All these things occur, but does anyone really expect each newspaper to be without broad attitudes that affect news and comment values? An illustration of the sort of editorial influence validly attempted and resisted is the story that Financial Review cartoonist Ward O'Neill tells of his time at The Australian in the early 1970s with Bruce Petty:

I do remember one story about Bruce. It was the middle of the Vietnamese peace negotiations. There was this Henry Kissinger authorised, you know, this bombing of Cambodia that basically; I think it killed about 100000 people. [...] And Bruce did this cartoon of Henry Kissinger coming back to the negotiating table and pulling his seat in, with his hands covered in blood. And The Australian didn't want him to do that. I think they might have forced him to change that, and, really, that was the entire point of the cartoon; that his hands were sort of covered in blood' (Interviewed, 15 April 2004).

It is hard to be certain three decades after the fact, but it seems probable that the cartoon opposite is the one O'Neill was referring to. There are alternative explanations of this cartoon, each of which has a bearing on our argument. The immediate context is the Christmas bombing of late 1972 (mostly of Vietnam) which was part of Nixon and Kissinger's endgame in Vietnam. It was intended to be a massive show of military power that provided a warning 


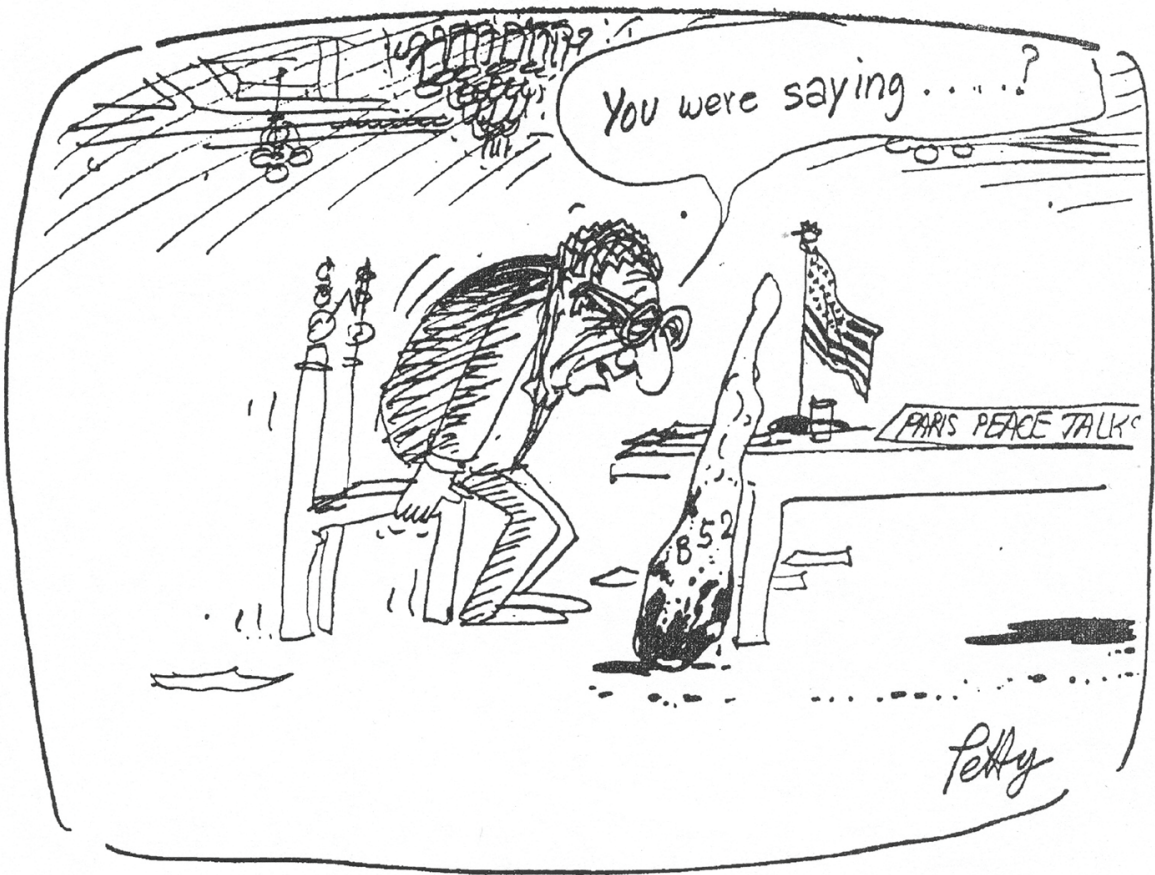

Bruce Petty: The Australian, 3 January 1973.

to the North Vietnamese to hurry them back to the negotiating table in Paris; the sequel was the US withdrawal of troops early in 1973.

If Petty originally drew Kissinger's hands covered in blood rather than the ugly club labeled B 52, the cartoon might have had a little more force, but it would be hard to argue that it has been much diminished, or that its meaning has been altered in any significant way. An alternative explanation is that this is not the cartoon O'Neill remembers, and that there was another cartoon dealing with Cambodia that had Kissinger's hands covered in blood which was completely pulled by an editor. If that were so, it would be extremely tempting to see this cartoon as a payback for the earlier editorial restraint. Either way, it appears that the lot of the cartoonist in 1973 was one of considerable if not untrammeled freedom. O'Neill goes on to explain how Petty, admittedly the pre-eminent cartoonist of the time managed relations with his editor: 
[Bruce Petty] worked up at one end of the art department. We were in this wedge-shaped room that went down to a point. Bruce was right at the end of the room. And Owen Thomson [editor of The Australian, 1971-73] would come in. It was really instructive, because he'd come in and he'd talk to Bruce and he'd try and impress upon him various points - none of which really matter; they were just the company or the Murdoch line or whatever it was. And Bruce, would just go 'Yeh, yeh, s'pose so, yeh, yeh' and he never argued, so there was no way Owen Thomson could come in and pick a fight with him. I've never seen him lose his temper, raise his voice. It's not to say he's agreeable, because he clearly doesn't agree with a lot, but he maintains his own position on things.

But he's not an aggressive person at all, and newspapers are often quite an aggressive environment. And he's a genuinely liked person by a very wide range of people politically. They' $d$ come in and they'd try and change his mind, and he'd certainly agree to hear them out. And then he'd go away and do exactly what he wanted to do. If somebody made a reasonable point, he would take that on board, but you could be quite confident that he would always make up his own mind. Any decision he made wouldn't be contaminated by fear of the boss, or fear of getting the sack. He's a principled person. (Interviewed, April 15, 2004)

This anecdotal illustration of the way influence expressed but not insisted upon, seems to be fairly typical of the way cartoonists have been treated in recent decades. While few can claim to be so calm as Petty by nature, each would like to think of themselves as equivalently independent-minded. Editorial nagging and fear of the sack must have influenced many individual decisions by cartoonists over the years, but their claim to retain a very large measure of independence is borne out, at least by our research into recent federal elections. Editors and proprietors seem to recognise that a cartoonist cannot easily be tame and funny at the same time, and funny cartoonists help them sell newspapers. Where the editorial line and the bottom line are in conflict, even the most ideological editors and proprietors know where their loyalties lie. Over time, of course, they can employ cartoonists who suit their world-view-for example, Rupert Murdoch's shift to the right can be seen clearly in the replacement of Bruce Petty by the right wing larrikin Larry Pickering at The Australian in early 1976 - but that only becomes a problem if there is an unhealthily limited range of media owners in a market(!). 


\section{External pressures}

There are at least three kinds of pressure that can be applied to cartoonists: pressure from lobby groups, from politicians and parties, and from corporate interests. Should cartoonists take to illustrating business news more - and, given the shift of power from traditional politics to the corporate sector in recent decades, it is something they should consider-more evidence of corporate pressure may come to light. At present, however, we lack even anecdotal evidence of threats by unhappy magnates to remove advertising from a paper over a cartoon that injured their brand or self-esteem, so we cannot even speculate whether this sort of pressure is significant.

The best evidence that politicians fear cartoonists comes from their actions. In totalitarian regimes they dictate to them, in less than liberal democracies they silence them or force them from the country, and in democracies with well-developed traditions of press freedom they flatter them. Geoff Pryor cartoonist with the Canberra Times, informed the audience at the 2000 Australasian Political Studies Association Conference, that a cartoonist can sit by the phone the morning after caricaturing a young politician for the first time, and practically count down until the call requesting the original comes in. There is a degree of machismo about this, and a sense of having 'made it', but one should not underestimate the element of insurance against future trouble in it. Australian politicians do try to develop a reputation as people who can take a joke with the practising cartoonists. Some even try to develop personal relationships with individuals, but the cartoonists tend to resist this.

Jockeying politicians for sympathy with cartoonists is no serious affront to the freedom of the press and represents no more than politicians doing their job, trying to massage their public image. Where politicians do occasionally seek undue influence is in complaining to editors about their cartoonists. If the editors protect their cartoonists, which they normally do, then a prime minister or premier whingeing about the unfairness of being drawn as a clown or a crook is probably no more than a colourful part of the rich tapestry of public life. Cartoonists are not easily cowed by abuse (direct or relayed) from the subjects of their ridicule; they more likely to be pleased that politicians are paying attention to them rather than being worried about hurting their feelings. However, this sort of thing is a pressure on their work, and it may wear them down over time.

Moreover, just occasionally there is some evidence that informal political pressure tempers and editor's mood. The late Les Tanner, long-term car- 
toonist with The Age, believed that Victorian Premier, Jeff Kennett, put pressure on the paper after his lampooning of Kennett with a persistent foot-inmouth caricature:

\begin{abstract}
My freedom from censorship lasted until the advent of Jeff Kennett. I was inclined to send him up, and did a cartoon of him with his foot in his mouth which later became a sort of current symbol. When he started to mount a counterattack on The Age there was an interesting disinclination to run cartoons critical of him. Fortunately by that time I'd reached 70 , and it was one of the many deciding factors that led to my retirement. (Tanner, cited in Turner, 2000)
\end{abstract}

However, while it is not uncommon for cartoonists to report that their editors have experienced the admonishment of political leaders, as long as cartoons remain safe from defamation it is clear that such pleas by leaders are largely ineffectual (Interview, 1 May 2004).

\title{
'Bad taste'
}

One of the main roles of satire is to shock an audience into a recognition that things are not as good as some would have us believe. Dealing provocatively with taboo topics is, consequently, one of the abiding pre-occupations of any cartoonist who ever seeks to be more than a tame comic entertainer. On the other hand, the medium in which cartoons are published, the newspaper, exerts a countervailing conservative pressure on subject matter and presentation. The question of 'bad taste' must be viewed within the context of the editor's responsibility to present a 'family paper', that is, the audience is the wider community not a specific section within. As Bruce Petty observes 'Both The Age and The Australian are family newspapers and have to appeal to a spectrum of Australians. Somehow I know the parameters and the editors know I do' (cited in Turner, 2000). Cartoonists may find their editors overly cautious on matters of taste but this does not equate to suffering censorship. To clarify this point, consider the example of Peter Nicholson who informed the audience at the 2000 Australasian Political Studies Association conference that his editor was unwilling to publish due to 'bad taste'. Of considerable satirical merit the cartoon addressed the topical question of the government's refusal to say 'sorry' to Aboriginal Australians and, in general, to seek reconciliation between black and white Australia. It depicted Prime Minister 
Howard sitting in the red dust adjacent Uluru, cross legged. He is blowing hard into a didgeridoo. His extended cheeks are accompanied by a large puff emitting from his anus - the cartoon's caption read, 'Reconciliation'.

Prudish editors may be a problem, as long-serving cartoonist at The Age, Ron Tandberg, explains

\begin{abstract}
One night I had a cartoon of a ballet dancer who defected to the West. I had him leaping off the stage with this slight bulge in his tights which every self-respecting male ballet dance has. It wasn't overdrawn. The next day it was in the country edition, but when I saw the next edition the bulge had been removed. So I went up to the main desk and said, 'Oh, you're the bloke who castrates my ballet dancer between editions'. I had a word with the editor, and he agreed that I was right, and that my stuff wouldn't be interfered with in future. (Tandberg, cited in Turner, 2000)
\end{abstract}

Earlier we used the metaphor of the canary down the mine to describe the role of cartoonists as indicators of the level of free speech in a society. Nowhere is this clearer than on the topic of 'good taste' in the representation of sex and violence. Compare the brilliant but austere social criticism by George Molnar in the 1950s and 60s to Michael Leunig's far more unbuttoned work of the 1990s and one can see more than a contrast of individual temperaments. The contrast also provides quite an accurate indication of the movement in public standards in what can be shown. Many cartoonists have stories of having cartoons knocked back on grounds of taste, and that this should be an area of constant negotiation of shifting standards seems to us to be a healthy sign. Far more explicit images appear in more specialised media (films, magazines, web sites, etc.) but cartoonists have the joker's licence to be boundary riders of the representable in the public sphere. It is in their nature to push the boundaries, and fair enough for those boundaries to push back from time to time.

\title{
Conclusion: Cartooning and responsibility
}

The boundaries of public morality are one thing, ideological good taste quite another. We will finish by commenting on whether and how cartoonists should feel constrained by a sense of responsibility that mirrors or differs from the responsibility expected of journalists. Recently Michael Hogan argued that 
political cartoons encourage public cynicism toward democratic institutions, leaders, parties and parliament and that if not checked, in some manner, this presents a problem for democracy in Australia. While stopping short of advocating any formal censorship for cartoons it is clear that he believes cartoonists should enjoy no special licence, arguing that it is possible to draw analogy between cartooning and political journalism:

The question I wish to ask here is whether the same criteria of balance and avoidance of bias should apply to cartoonists as are regularly demanded of journalists who use words and graphic images in their stories or commentaries. Should cartoonists be accorded extra licence? It is not immediately obvious to me why they should be. Is their function fundamentally different from that of journalists - that cartoonists should be able to lampoon mercilessly, while journalists should beware - or is the cartoonist simply a journalist who uses visual humour? (Hogan, 2001)

We disagree with the drift of these apparently rhetorical questions, and have disagreed at length elsewhere (Manning \& Phiddian, 2004). Cartoonists implicitly make quite a different claim in relation to the truth value of their work from that made by journalists. As we have explained earlier, in relation to the law of libel, cartoonists are clearly involved in comment rather than reporting, and the comment they make is obviously and recognisably extravagant.

It is important also, in our opinion, that cartooning not be caught by a definition of fair comment more onerous than the strict legal definition of 'fair':

The term 'fair' is misleading for it suggests that the comment is assessed to determine whether reasonable people might agree with it. In fact, honesty is critical, not reasonableness. The test is: could a person honestly hold the opinion expressed? Provided the opinion satisfies this test, the fact that it amounts to a severe, exaggerated, prejudiced or 'wrong-headed' criticism is irrelevant. (Walker, 1989)

It is obvious that cartoonists would fail as entertainers if they felt constrained to be cautiously reasonable in their work. Just as importantly, however, we think the right of public satirists to risk irresponsibly needs to be affirmed. 
The less they feel under legal, ethical, or corporate pressure to be responsible, the better they will do their job in that most complex of socio-political phenomena, a free press. Cartoonists are licensed skeptics who provide one important medium where the spin that is epidemic in public life can be countered, one forum where the shameless can be shamed and open secrets spoken. Their licence is not a simple freedom, but comes from a complicated mix of social, political, historical, and legal factors. It may be possible to have freedom of expression and a free press without much freedom of political cartoonists, but we cannot think of any instances where this has been so. Their presence is always a healthy sign, even if their work does sponsor some public cynicism. They are subject to the various formal and informal pressures we have outlined above, so it is clear that their licence is not absolute, and the fact that it is not absolute is no scandal. That their licence should be as extensive as possible is one, not insignificant, indication that a liberal democratic polity seeks to practice its ideals.

\section{References}

ABC television. (2002, May 6). Lost Leunig. Mediawatch. (Retrieved, 12 March 2004): www.abc.net.au/mediawatch/transcripts/060502_s5.htm

Bennett, A and C. Satullo. (2003, August). A cartoon, an uproar, then a useful dialogue, Philadelphia Inquirer.

Geipel, J. (1972). The cartoon: A short history of graphic comedy and satire . Newton Abbot: David and Charles.

Gombrich, E. H. (1978). Meditations on a hobby horse. Oxford: Phaidon Press.

Griffen-Foley, B. (1999). The house of Packer: The making of a media empire. St Leonards: Allen and Unwin.

Harvey, C. (2003, August 21). Kiwi cartoonist sacked. The Australian.

Hogan, M, (2001). Cartoonists and political cynicism. Drawing Board. July, 2 (1): $27-50$.

Keyer, J. (2003, September, 5). New Zealand cartoonist, fired amid controversy over drawings critical of Israel, says he's not anti-Semitic. Associated Press Newswires.

Leibovich-Dar, S. (2003, August 29). Drawing the line, interview with Malcolm Evans. Haaretz.

Levy, F and Perloe, A. (2003, August 7). Star makes waves in Jewish circles: 'Philadelphia Inquirer' cartoon spurs fury. Jewish Exponent. Vol. 214, Number 19.

Lindesay, V. (1970). The inked-in image: A survey of Australian comic art. Melbourne: Heinemann,

Press, C. (1981). The political cartoon. Rutherford: Fairleigh Dickinson.

Schleider, A. (2003, August 3). Political cartoon raises ire in Philadelphia. The Forward (Jewish-American journal) www.forward.com/issues/2003/03.08.15/ news14.html. 


\section{MEDIA ETHICS AND ACCOUNTABILITY}

Seymour-Ure, C. (1997). Drawn and quartered: How wide a world for the political cartoon? The Hocken Lecture 1996. The Hocken Library \& the New Zealand Cartoon Archive Trust. Dunedin: The Printing Department, University of Otago, pp. $1-43$;

Turner, A. (2000). In their image: Contemporary Australian cartoonists. Canberra: National Library of Australia.

Walker, S. (1989). The law of journalism in Australia. Sydney: Law Book Company.

Dr Haydon Manning is an academic with the School of Political and International Studies and Dr Robert Phiddian is with the Department of English at Flinders University, Adelaide, Australia. The copyright cartoons are published with permission. Cartoonist Malcolm Evans wrote his own account of Zionist pressure and this was published in PJR, 'The political cartoonist's right to freedom of expression', 10(2): 71-80.

haydon.manning@flinders.edu.au

\section{JEANZ CONFERENCE 2005}

\section{CALL FOR PAPERS}

Anyone wishing to submit a paper for the Jeanz 2005 Conference at the Waikato Institute of Technology (Wintec), Hamilton, on 7-9 December 2005 is invited to submit a 300-word abstract to Grant Hannis, Head of Journalism at Massey University, by 31 October 2005.

There is no specific conference theme, and papers are welcome on any aspect of current journalism research.

Please submit your abstract by email and include all your contact details:

\section{g.d.hannis@massey.ac.nz}

Full conference details on the Jeanz website:

www.jeanz.org.nz 